\title{
Mitochondrial genetic differentiation across populations of the malaria vector Anopheles lesteri from China (Diptera: Culicidae)
}

\author{
Manni Yang, Yajun $\mathrm{Ma}^{*}$ and Jing Wu
}

\begin{abstract}
Background: Anopheles lesteri is a primary vector of Plasmodium spp. in central China. A complete understanding of vector population structure and the processes responsible for the differentiation is important to the vectorbased malaria control programmes and for identifying heterogeneity in disease transmission as a result of discrete vector populations. There is no adequate An. lesteri population genetic data available.

Methods: Polymorphism of sequence variations in mitochondrial COIl and Cytb genes were assessed to explore the level of genetic variability and differentiation among six populations of An. lesteri from China.

Results: There were 30 (4.37\%) and 21 (5.33\%) polymorphic sites for mtDNA-COII and Cytb gene, respectively. Totally 31 COII and 30 Cytb haplotypes were obtained. The range of $F_{S T}$ values was from 0.101 to 0.655 by mtDNACOII, and 0.029 to 0.231 by Cytb gene. The analysis of molecular variance (AMOVA) showed that the percentage of variation within populations $(65.83 \%, 88.48 \%)$ was greater than that among populations $(34.17 \%, 11.52 \%)$ using both genes. The Tajima's $D$ and Fu's Fs values were all negative, except Tajima's $D$ values of YN and HNB populations, which suggest a large number of low-frequency mutations in populations and the populations were in expansion proceeding.

Conclusions: Levels of genetic variation within An. lesteri populations were higher than among them. While these results may suggest considerable levels of gene flow, other explanations, such as the effect of historical population perturbations can also be hypothesized.
\end{abstract}

\section{Background}

Anopheles lesteri, which belongs to the Hyrcanus group of the genus Anopheles is a primary vector of malaria in central China [1]. Genetically-based methods have been proposed for malaria vector control. These methods focus mainly in altering vectorial capacity through the genetic modification of natural vector populations by means of introducing refractoriness genes or by sterile insect technologies [2]. Knowledge of the genetic structure of vector species is, therefore, an essential requirement as it should contribute not only to predict the spread of genes of interest, such as insecticide resistance or refractory genes, but also to identify heterogeneities in disease transmission due to distinct vector

\footnotetext{
* Correspondence: yajunm@yahoo.com.cn

* Correspondence: yajunm@yahoo.com.cn
Department of Pathogen Biology, Second Military Medical University, Shanghai 200433, China
}

(c) 2011 Yang et al; licensee BioMed Central Ltd. This is an Open Access article distributed under the terms of the Creative Commons Attribution License (http://creativecommons.org/licenses/by/2.0), which permits unrestricted use, distribution, and reproduction in any medium, provided the original work is properly cited.

populations [3]. A complete understanding of vector population structure and the processes responsible for the distribution of differentiation is important to vectorbased malaria control programmes and for identifying heterogeneity in disease transmission as a result of discrete vector populations [4]. Susceptibility to Plasmodium infection, survival and reproductive rates, degree of anthropophily, and the epidemiology of malaria in the human host may all be affected by genetic variation in vector populations [5].

Anopheles lesteri is almost morphologically undistinguishable from its sibling species because of lacking the objective and stable identification characters, so the taxonomic status on An. lesteri in China has revised many times. Xu and Feng [6] regarded the Chinese "An. lesteri" as a new subspecies An. lesteri anthropophagus because it was distinct from both An. lesteri lesteri from the Philippines and An. lesteri paraliae [7] from 
Malaysia in bionomics as well as morphology. The subspecies was later elevated to a full species rank [8]. However, the second internal transcribed spacer (ITS2) of ribosomal DNA (rDNA) of An. anthropophagus in China was similar to that of An. lesteri from the Philippines, South Korea, Guam and Japan $[9,10]$. The molecular evidence strongly support that An. anthropophagus is the synonym of $A n$. lesteri.

Anopheles lesteri exhibits variation in ecology [11], morphology [12], chromosomes [12], and random amplified polymorphic DNA (RAPD) markers [13]. Furthermore, $A n$. lesteri was not considered as malaria vector in Guam and Philippines, but had high transmission capacity of malaria in central China [11,14], and a certain transmission capacity in South Korea and Japan $[15,16]$. Despite its significance in malaria transmission, only a few studies on population genetics have been conducted [13]. Many genes of mtDNA were used to analyse the genetic variation and population structure of the Anopheline mosquitoes, such as cytochrome subunit I (COI) [17-20], cytochrome subunit II (COII) [21,22], control region [23], NADH dehydrogenase subunit 4 [24] and subunit 5 [4,25-29]. The present study aimed to estimate genetic variability and population structure and to infer the extent of gene flow among $A n$. lesteri populations from China based on mtDNA-COII and cytochrome B (Cytb) genes sequences.

\section{Methods}

\section{Mosquito collections and species identification}

Wild adult An. lesteri were collected from 2004 to 2007, by using indoor light traps and human landing catches at human living room and livestock corrals. The eight collection sites in China were located from $22^{\circ} 17^{\prime} \mathrm{N}$ to $39^{\circ}$ $58^{\prime} \mathrm{N}$, and $103^{\circ} 29^{\prime} \mathrm{E}$ to $123^{\circ} 50^{\prime} \mathrm{E}$ (Table 1 Figure 1 ). The HNB and YN populations consisted of specimens pools from two or three sites in proximity to each other, as stated in Table 1 . The distances between sites were below $50 \mathrm{~km}$. There were total five field populations and a laboratory colony, with JS population in this study.
Adult mosquitoes of $A n$. hyrcanus group were identified by morphology using the identification keys of $\mathrm{Lu}$ et al [14]. Specimens were kept individually in silica gel filled tubes at $4^{\circ} \mathrm{C}$, until DNA extraction was performed according to Collins et al [30]. Anopheles lesteri species identification was done by a PCR assay based on rDNAITS2 markers previously described in Ma et al [31].

\section{mtDNA-COII and Cytb genes amplification and sequencing}

Sequence variation was examined in the mtDNA-COII and the Cytb genes. The COII and Cytb regions were amplified in $50 \mu \mathrm{L}$ reaction mixtures containing $1 \times$ reaction buffer (QIAGEN, Courtaboeuf, France), 0.1 $\mathrm{mM}$ of each dNTP (Eurogentec, Angers, France), 1 unit of Taq DNA polymerase, $0.1 \mu \mathrm{M}$ each of the forward and reverse primers and $1.5 \mu \mathrm{L}$ genomic DNA. The COII gene was amplified using primers COIIF (5'- TCT AAT ATG GCA GAT TAG TGC A -3', forward) and COIIR (5'- ACT TGC TTT CAG TCA TCT AAT G -3', reverse), and the $\mathrm{Cytb}$ gene using primers $\mathrm{CytbF}$ (5'-GGA CAA ATA TCA TTT TGA GGA GCA ACA G-3', forward) and CytbR (5'- ATT ACT CCT CCT AGC TTA TTA GGA ATT G -3', reverse). The cycle conditions in PTC-100 Peltier Thermal Cycler included an initial denaturation step at $94^{\circ} \mathrm{C}$ for $2 \mathrm{~min}$, followed by 30 cycles at $94^{\circ} \mathrm{C}$ for $30 \mathrm{~s}, 50^{\circ} \mathrm{C}$ for $30 \mathrm{~s}$ and $72^{\circ} \mathrm{C}$ for $30 \mathrm{~s}$, with a final extension step at $72^{\circ} \mathrm{C}$ for $8 \mathrm{~min}$. After electrophoresis, PCR products were purified and used for sequencing in both directions with the previous primers, on an ABI 3730 automatic sequencer (Applied Biosystems). Sequences were inspected and corrected, where necessary, using SEQSCAPE software (Applied Biosystems).

\section{Data analyses}

Multiple sequence alignments for each gene were performed using MEGA 4.0 [32] and CLUSTAL $\times$ [33]. The sequences polymorphism was assessed with MEGA 4.0. A haplotype networks and outgroup probability of

Table 1 The collecting data of Anopheles lesteri mosquito populations in this study

\begin{tabular}{|c|c|c|c|c|c|}
\hline Population Code & Collecting site & Collecting date & Sample size & Latitude (N) & Longitude (E) \\
\hline$\overline{G D}$ & Zhuhai, Guangdong & Oct. 2007 & 22 & $22^{\circ} 17^{\prime}$ & $113^{\circ} 30^{\prime}$ \\
\hline \multirow[t]{2}{*}{ YN } & Yanjing, Yunnan & June 2006 & 9 & $28^{\circ} 60^{\prime}$ & $104^{\circ} 13^{\prime}$ \\
\hline & Junlian, Sichuan & June 2006 & 4 & $28^{\circ} 10^{\prime}$ & $104^{\circ} 34^{\prime}$ \\
\hline SC & Pujiang, Sichuan & June 2006 & 23 & $30^{\circ} 14^{\prime}$ & $103^{\circ} 29^{\prime}$ \\
\hline \multirow[t]{2}{*}{ HNB } & Guangshui \& Suizhou, Hubei & June 2007 & 8 & $31^{\circ} 41^{\prime}-31^{\circ} 52^{\prime}$ & $113^{\circ} 15^{\prime}-113^{\circ} 47^{\prime}$ \\
\hline & Tongbai, Heinan & June 2007 & 5 & $32^{\circ} 29^{\prime}$ & $113^{\circ} 23^{\prime}$ \\
\hline$J S^{*}$ & Xuyi, Jiangsu & June 1985 & 17 & $32^{\circ} 54^{\prime}$ & $118^{\circ} 34^{\prime}$ \\
\hline LN & Donggang, Liaoning & June 2004 & 28 & $39^{\circ} 58^{\prime}$ & $123^{\circ} 50^{\prime}$ \\
\hline
\end{tabular}

* The collecting site and date of laboratory colony were original information. The mosquitoes were kept at $26 \pm 1{ }^{\circ} \mathrm{C}$ and $65 \pm 5 \%$ (RH), under a $12: 12 \mathrm{hr}$ (light: dark) photoperiod. 


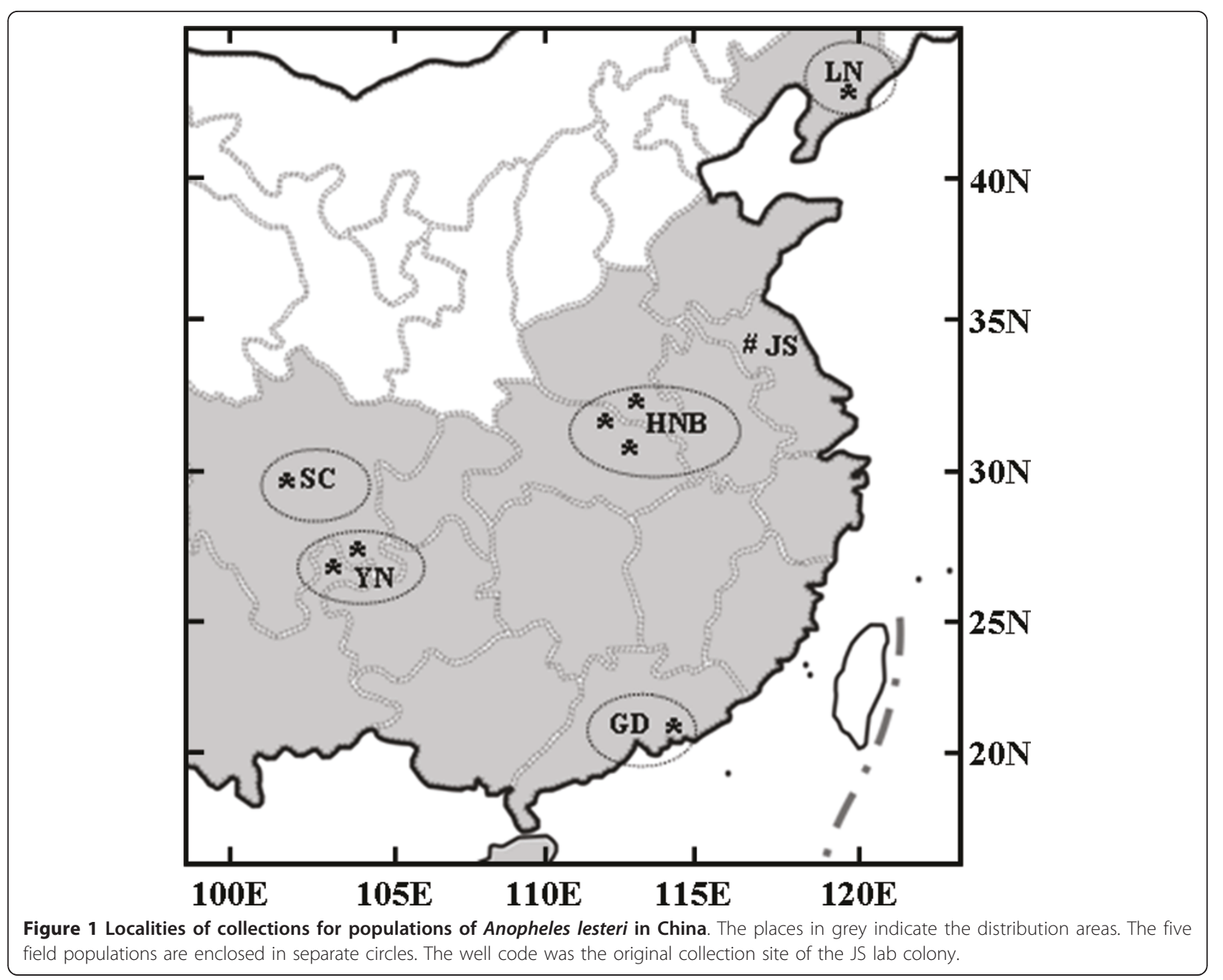

the haplotypes were constructed based on statistical parsimony using TCS 1.21 [34].

The parameters $\theta_{\pi}$ equivalent to the average pairwise number of differences between sequences [35], $\theta_{\mathrm{s}}$ equivalent to the number of segregating nucleotide sites per sequence [36], and haplotypes diversity $(h)$ were estimated for COII and Cytb polymorphism within populations. The population genetic structure was analysed with 5 field populations, and assessed by analyzing molecular variance with ARLEQUIN 3.11 [37]. The percentage of sequence divergence within and between populations was calculated based on Nei and Li [38], and pairwise $F_{S T}$ values for short-term genetic distance between populations were estimated with the methods of Slatkin (1995) [39] and tested for significance by permutation. Mismatch distributions were calculated using ARLEQUIN 3.11, and the neutrality tests were evaluated by Tajima's $D$ and Fu's Fs. Isolation by geographical distance was assessed by GENEPOP 4.0.10 [40] using Mantel test.

\section{Results}

Sequences characteristics of mtDNA-COII

One hundred and sixteen An. lesteri mosquitoes were distinguished by PCR assay from China (Table 1). A 686 bp COII sequence was determined in 88 mosquitoes, and a Cytb fragment of 394 bp was obtained from 112 mosquitoes. All segregating sites and the sequence variants (haplotypes) are shown in Figures 2 and 3. The summary statistics for both genes are given in Table 2 . Across the whole dataset, there were 30 (4.37\%) and 21 (5.33\%) polymorphic sites for COII and Cytb, respectively. This low number of variable sites resulted in low nucleotide diversity and low haplotype diversity across samples. The $\theta_{\mathrm{S}}$ of overall field populations was from $0.581 \pm 0.435 \mathrm{SD}$ to $4.285 \pm 1.709 \mathrm{SD}$ for COII, and $0.274 \pm 0.274 \mathrm{SD}$ to $3.545 \pm 1.655 \mathrm{SD}$ for Cytb; $\theta_{\pi}$ was from $0.477 \pm 0.485 \mathrm{SD}$ to $2.598 \pm 1.606 \mathrm{SD}$ for COII, $0.091 \pm 0.188 \mathrm{SD}$ to $2.231 \pm 1.476 \mathrm{SD}$ for Cytb and $h$ was from $0.005 \pm 0.003 S D$ to $0.000 \pm 0.000 S D$ (Table 2). 


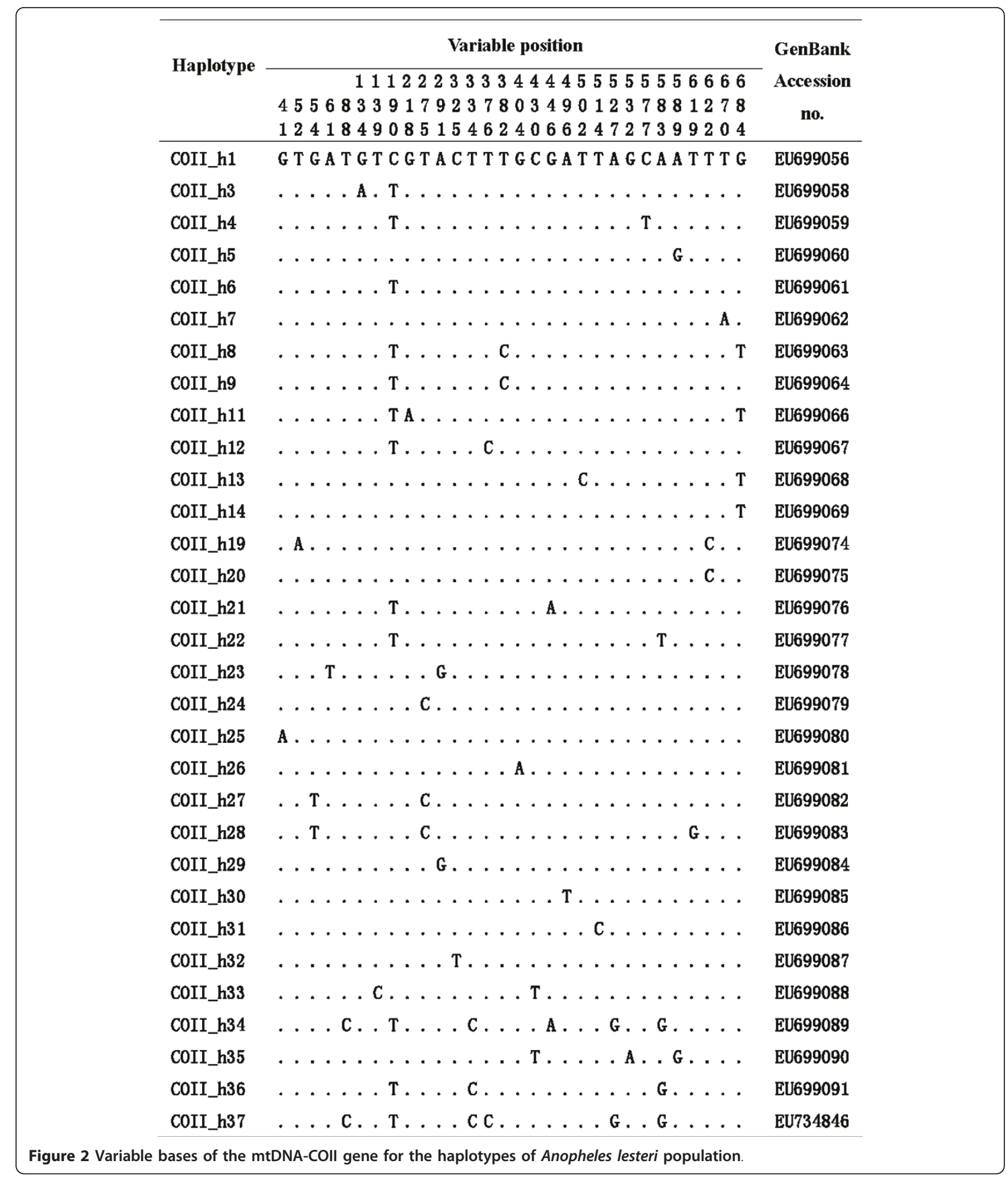

Among the 88 COII sequences, 31 haplotypes were found. Four haplotypes of COII_1, COII_5, COII_6 and COII_20 occurred in more than one population, the frequency was $12.90 \%(4 / 31)$. Thirty of 112 Cytb haplotypes were observed. Three haplotypes of Cytb_1,
Cytb_2 and Cytb_4 were shared, especially; Cytb_2 occurred in all populations (Table 2). Haplotype networks showed that An. lesteri haplotypes derived from a single common ancestral COII haplotype and two ancestral Cytb haplotypes (Figure 4). 


\begin{tabular}{|c|c|c|c|c|c|c|c|c|c|c|c|c|c|c|c|c|c|c|c|c|c|c|}
\hline \multirow{4}{*}{ Haplotype } & \multicolumn{21}{|c|}{ Variable position } & \multirow{4}{*}{$\begin{array}{c}\text { GenBank } \\
\text { Accession } \\
\text { no. }\end{array}$} \\
\hline & & & & & & & & 1 & 1 & 1 & 2 & 2 & 2 & 2 & 2 & 3 & 3 & 3 & 3 & & & \\
\hline & 3 & 1 & 2 & 3 & 5 & 7 & 8 & 1 & 4 & 7 & 2 & 4 & 5 & 6 & 8 & 1 & 1 & 3 & 5 & 7 & 7 & \\
\hline & 2 & 4 & 3 & 4 & 8 & 6 & 8 & 2 & 5 & 0 & 0 & 4 & 7 & 9 & 7 & 3 & 6 & 1 & 2 & 1 & 3 & \\
\hline Cytb_1 & $\mathrm{C}$ & G & $\mathrm{C}$ & $\mathrm{T}$ & A & A & G & $\mathrm{T}$ & $\mathrm{T}$ & G & $\mathrm{C}$ & $\mathrm{T}$ & G & A & G & $\mathrm{T}$ & A & $\mathrm{C}$ & $\mathrm{T}$ & $\mathrm{T}$ & A & EU699092 \\
\hline Cytb_2 & . & . & . & . & . & • & A & 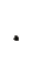 & & ${ }^{*}$ & . & . & . & 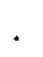 & $\cdot$ & . & . & A & . & . & . & EU699093 \\
\hline Cytb_4 & . & . & . & . & 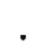 & . & A & 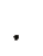 & . & $\mathbf{A}$ & . & . & . & . & . & . & . & A & . & . & . & EU699095 \\
\hline Cytb_5 & . & . & . & . & 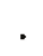 & - & . & $\cdot$ & & $\cdot$ & . & C & . & . & $\cdot$ & . & . & . & . & . & . & EU699096 \\
\hline Cytb_6 & . & . & . & . & . & C & A & . & & A & . & . & . & . & $\cdot$ & . & . & A & . & . & . & EU699097 \\
\hline Cytb_7 & . & . & . & . & . & . & A & . & & - & . & . & . & . & $\cdot$ & . & . & . & . & . & . & EU699098 \\
\hline Cytb_8 & . & . & . & . & G & . & A & . & 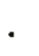 & A & . & . & . & . & . & . & . & A & . & . & . & EU699099 \\
\hline Cytb_10 & . & . & . & . & . & . & A & . & & . & . & . & . & . & $\cdot$ & C & . & A & . & . & . & EU699101 \\
\hline Cytb_11 & . & . & . & . & 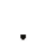 & - & A & . & & • & . & . & . & . & $\cdot$ & . & G & A & G & G & . & EU699102 \\
\hline Cytb_12 & . & . & . & . & G & G & A & . & . & A & . & . & . & . & . & . & . & A & . & . & . & EU699103 \\
\hline Cytb_13 & . & . & . & $\mathrm{C}$ & • & . & A & . & C & . & . & . & . & . & . & . & . & A & . & . & . & EU699104 \\
\hline Cytb_14 & . & A & . & . & • & - & A & $\mathrm{C}$ & & • & . & . & . & . & . & . & . & A & • & . & . & EU699105 \\
\hline Cytb_20 & . & . & . & . & $\cdot$ & - & A & . & & • & . & . & . & . & $\mathrm{T}$ & . & . & A & . & . & . & EU699111 \\
\hline Cytb_21 & . & . & . & . & • & . & A & C & & . & . & . & . & . & . & . & . & A & $\cdot$ & . & . & EU699112 \\
\hline Cytb_24 & . & . & . & . & • & - & A & $\mathrm{C}$ & & . & . & . & . & G & . & . & . & A & . & . & . & EU699115 \\
\hline Cytb_26 & . & . & . & . & - & - & A & . & & . & . & . & . & . & . & $C$ & . & $\mathrm{A}$ & . & G & G & EU699117 \\
\hline Cytb_27 & . & . & . & . & . & . & A & . & & . & . & . & . & . & . & $\mathrm{C}$ & . & A & . & . & G & EU699118 \\
\hline Cytb_28 & . & . & $\mathrm{T}$ & ' & . & . & A & . & & • & . & . & . & . & . & . & . & A & . & . & $\cdot$ & EU699119 \\
\hline Cytb_29 & . & . & . & C & - & - & A & $\mathrm{C}$ & & • & . & . & . & G & . & . & . & A & . & . & . & EU699120 \\
\hline Cytb_30 & $\mathrm{T}$ & . & . & . & . & . & A & C & & . & . & . & . & . & . & . & . & A & . & . & . & EU699121 \\
\hline Cytb_31 & $\mathrm{T}$ & . & . & . & . & . & A & . & & • & . & . & . & . & . & . & . & A & . & . & . & EU699122 \\
\hline Cytb_32 & . & . & . & C & . & . & A & . & & $\mathbf{A}$ & . & . & . & . & . & . & . & A & . & . & . & EU699123 \\
\hline Cytb_33 & . & . & . & C & G & . & A & . & & A & . & . & . & . & . & $\mathrm{C}$ & G & A & . & . & . & EU699124 \\
\hline Cytb_34 & . & . & . & . & . & - & A & . & & & $\mathrm{T}$ & . & . & . & . & . & . & A & $\cdot$ & . & . & EU699125 \\
\hline Cytb_35 & . & . & . & C & G & . & A & 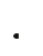 & & & . & . & . & . & . & C & . & A & . & . & . & EU699126 \\
\hline Cytb_36 & . & . & . & $\mathrm{C}$ & . & . & A & . & & & . & . & . & . & . & . & . & A & • & . & . & EU699127 \\
\hline Cytb_37 & . & . & - & . & 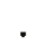 & - & A & . & & & . & C & . & . & . & . & . & A & . & . & 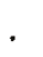 & EU699128 \\
\hline Cytb_38 & . & . & - & C & G & . & A & . & & A & . & . & $\cdot$ & . & . & $C$ & $\cdot$ & A & $\cdot$ & . & $\cdot$ & EU699129 \\
\hline Cytb_39 & . & . & - & . & - & . & A & & & & . & . & A & . & . & $\cdot$ & . & A & . & . & . & EU699130 \\
\hline Cytb_40 & $\cdot$ & - & • & C & G & - & A & & & A & $\mathrm{T}$ & $\cdot$ & $\cdot$ & - & . & $\mathrm{C}$ & $\cdot$ & A & . & . & • & EU699131 \\
\hline
\end{tabular}

Figure 3 Variable bases of the mtDNA-Cytb gene for the haplotypes of Anopheles lesteri population.

Population genetic structure of An. lesteri population

The genetic structure was analysed with GD, LN, YN, $\mathrm{SC}$ and $\mathrm{HNB}$ populations. The range values of paiwise $F_{S T}$ was from $0.101(\mathrm{GD} / \mathrm{LN})$ to $0.655(\mathrm{GD} / \mathrm{SC})$ with mtDNA-COII, and $0.029(\mathrm{HNB} / \mathrm{LN})$ to 0.231 (YN/SC) with Cytb (Table 3). A Mantel test was carried out, and the correlation coefficient for the $F_{S T}$ with geographical distance was 0.271 by COII $(P \geq 0.803)$ and 0.089 by Cytb $(P \geq 0.400)$, which was not significance based on 1,000 permutations. 
Table 2 Data summary for populations, haplotypes and nucleotide diversity of Anopheles lesteri

\begin{tabular}{|c|c|c|c|c|c|c|c|}
\hline Population & Gene & $\mathrm{N}$ & Haplotypes (n) & $S$ & $h( \pm \mathrm{SD})$ & $\theta_{\mathrm{s}}( \pm \mathrm{SD})$ & $\theta_{\pi}( \pm S D)$ \\
\hline \multirow[t]{2}{*}{ YN } & COII & 8 & $\mathbf{1}(2), 3(2), 4(2), \mathbf{5 ( 1 )}, \mathbf{6 ( 1 )}$ & 4 & $0.002 \pm 0.002$ & $1.543 \pm 0.961$ & $1.643 \pm 1.227$ \\
\hline & Cytb & 13 & $1(2), 2(5), 4(3), 5(1), 6(1), 7(1)$ & 5 & $0.004 \pm 0.003$ & $1.611 \pm 0.899$ & $1.615 \pm 1.147$ \\
\hline \multirow[t]{2}{*}{ HNB } & COII & 8 & 1(1), 8(1), 9(1), 11(1), 12(2), 13(1), 14(1) & 8 & $0.004 \pm 0.002$ & $2.314 \pm 1.308$ & $2.464 \pm 1.692$ \\
\hline & Cytb & 12 & 1(3), 2(2), 4(1), 8(1), 10(1), 11(1), 12(1), 13(1), 14(1) & 13 & $0.006 \pm 0.004$ & $3.545 \pm 1.655$ & $2.231 \pm 1.476$ \\
\hline \multirow[t]{2}{*}{ JS } & COII & 12 & 19(2), 20(10) & 1 & $0.000 \pm 0.002$ & $0.331 \pm 0.331$ & $0.303 \pm 0.379$ \\
\hline & Cytb & 17 & $2(17)$ & 0 & $0.000 \pm 0.000$ & $0.000 \pm 0.000$ & $0.000 \pm 0.000$ \\
\hline \multirow[t]{2}{*}{ SC } & COII & 18 & $6(3), 21(14), 22(1)$ & 2 & $0.001 \pm 0.001$ & $0.581 \pm 0.435$ & $0.477 \pm 0.485$ \\
\hline & Cytb & 22 & $2(21), 4(1)$ & 1 & $0.000 \pm 0.000$ & $0.274 \pm 0.274$ & $0.091 \pm 0.188$ \\
\hline \multirow[t]{2}{*}{ GD } & COII & 18 & $1(9), 23(1), 24(3), 25(1), 26(1), 27(1), 28(1), 29(1)$ & 7 & $0.002 \pm 0.001$ & $2.035 \pm 1.006$ & $1.288 \pm 0.946$ \\
\hline & Cytb & 21 & 2(6), 4(2), 20(1), 21(2), 24(2), 26(1), 27(3), 28(1), 29(1), 30(1), 31(1) & 10 & $0.005 \pm 0.003$ & $2.780 \pm 1.239$ & $2.076 \pm 1.350$ \\
\hline \multirow[t]{2}{*}{ LN } & COII & 24 & $\mathbf{1}(\mathbf{4}), \mathbf{5}(1), 7(1), \mathbf{2 0}(\mathbf{8}), 30(1), 31(1), 32(3), 33(1), 34(1), 35(1), 36(1), 37(1)$ & 15 & $0.005 \pm 0.002$ & $4.285 \pm 1.709$ & $2.598 \pm 1.606$ \\
\hline & Cytb & 27 & 2(14), 4(1), 32(1), 33(1), 34(1), 35(3), 36(1), 37(1), 38(2), 39(1), 40(1) & 9 & $0.005 \pm 0.003$ & $2.037 \pm 0.928$ & $1.926 \pm 1.255$ \\
\hline
\end{tabular}

$h$ is haplotype diversity, $S$ is the number of segregating sites and $\theta_{\mathrm{s}}$ and $\theta_{\pi}$ are the estimates of nucleotide diversity. The bold haplotypes occur in more than one population and the number in parentheses indicates the frequency of the haplotype.

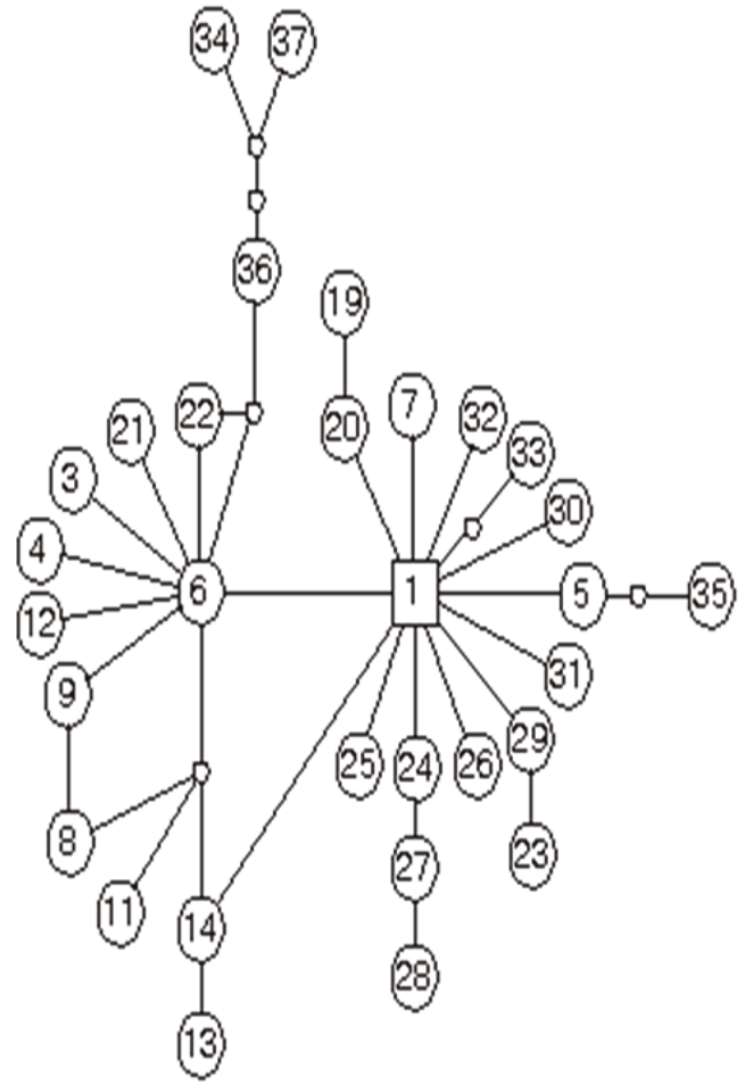

mtDNA-COII

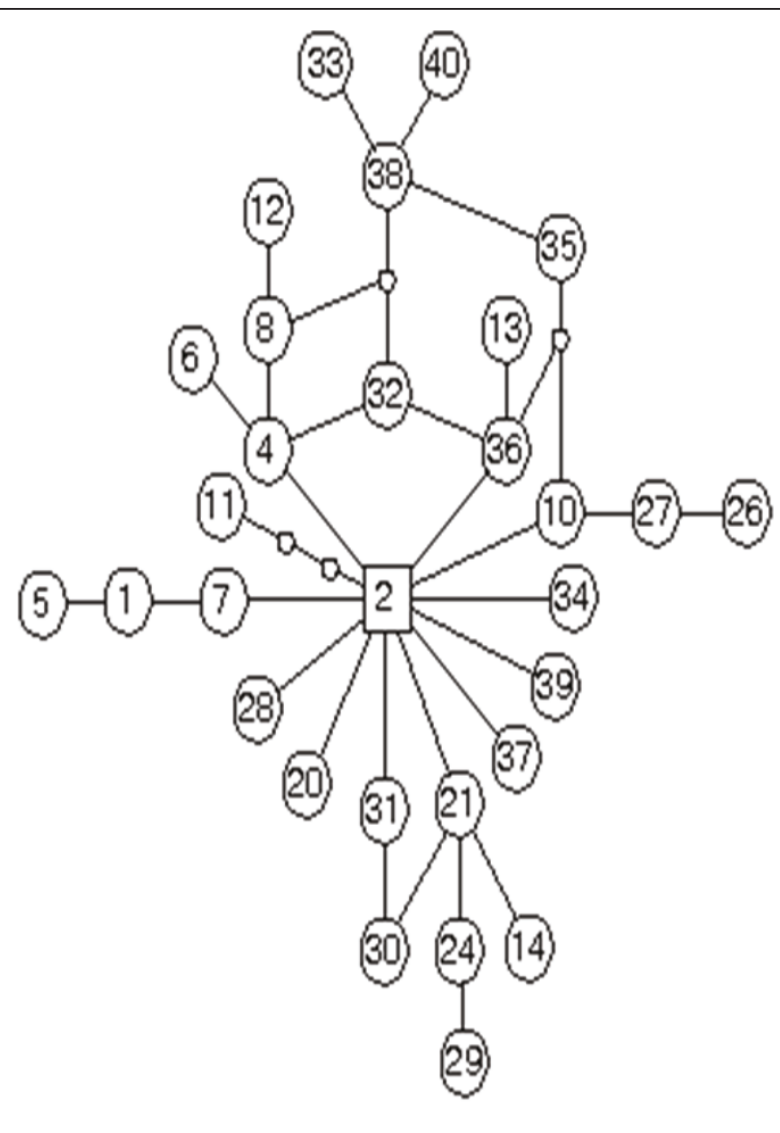

mtDNA-CytB

Figure 4 Genealogical relationships among haplotypes of two mtDNA genes estimated by TCS. The circle indicates one of haplotypes and the number in circle represents the type of haplotype. A unit branch represents one mutation. The empty circles indicate haplotypes that were not observed. 
Table 3 Pairwise genetic distance $\left(F_{S T}\right)$ for populations of Anopheles lesteri

\begin{tabular}{|c|c|c|c|c|c|}
\hline & YN & HNB & SC & GD & LN \\
\hline YN & $\begin{array}{c}\mathbf{0 . 3 4 5 /} \\
0.114\end{array}$ & 0.055 & $0.231^{*}$ & $0.128^{*}$ & $0.153^{*}$ \\
\hline HNB & 0.124 & $\begin{array}{c}\mathbf{0 . 3 2 4} / \\
0.096\end{array}$ & $0.125^{*}$ & $0.055^{*}$ & 0.029 \\
\hline SC & $0.500^{*}$ & $0.501 *$ & $\begin{array}{c}\mathbf{0 . 3 7 4} / \\
0.159\end{array}$ & $0.109^{*}$ & $0.172^{*}$ \\
\hline GD & $0.272^{*}$ & $0.319^{*}$ & $0.655^{*}$ & $\begin{array}{c}\mathbf{0 . 2 5 2} / \\
0.099\end{array}$ & $0.117^{*}$ \\
\hline LN & $0.135^{*}$ & $0.194^{*}$ & $0.455^{*}$ & $0.101 *$ & $\begin{array}{c}0.315 \\
0.103\end{array}$ \\
\hline
\end{tabular}

The pairwise values calculated by mtDNA-COII and Cytb gene are below and above the diagonal. The numbers along the diagonal are $F_{S T}$ values within population. The bold values are by COIl gene. ${ }^{*} P<0.05$.

In the hierarchical AMOVE, both the 'among populations' and 'within populations' variance components were considerable high, the latter was more contribution to total variances than the former (Table 4). The mean genetic divergence among populations was greater by COII (0.342) than Cytb (0.115).

The simulated mismatch distribution among the mtDNA-COII and Cytb haplotypes was smooth and unimodal peak, which coincide with the population expansion model. Although, observed value appeared multimodal, the result of variance test indicated the degree of coincidence between them was not significance ( $P \geq 0.00$ with COII, $P \geq 0.15$ with Cytb) [41]. The Tajima's $D$ and Fu's $F s$ values were all negative, except Tajima's $D$ values of YN and HNB populations (Table 5), which suggested a large number of low-frequency mutations in populations and the populations were in expansion proceeding. The strongly negative values for Fu's $F s$ suggested population growth and this is supported by the estimated values using COII gene from the rapid expansion model fitted in ARLEQUIN $\left(\tau=2 \mathrm{u} t=2.615, \theta_{0}=0.00-0.39, \theta_{1}=99\right.$ 999, $\mathrm{u}=$ per sequence mutation rate, $t=$ time since expansion, $N=$ effective number of females). With a mutation rate of $1 \times 10^{-8}$ per site per generation [42], these values suggested a change in population size from a few thousand females to $10^{8}$ females, in the range of 3970 years ago based on two generations of Anopheline mosquitoes in one month.
Table 5 Values of neutrality test for Anopheles lesteri populations by mtDNA genes

\begin{tabular}{|c|c|c|c|c|c|c|}
\hline & & YN & HNB & SC & GD & LN \\
\hline \multirow[t]{2}{*}{ Tajima's D } & COII & 0.283 & 0.303 & -0.438 & $-1.246^{*}$ & $-1.402^{*}$ \\
\hline & Cytb & 0.009 & $-1.498^{*}$ & -1.162 & -0.873 & -0.167 \\
\hline \multirow[t]{2}{*}{ Fu's Fs } & COII & -8.139 & $-\alpha$ & -28.504 & -26.580 & -26.580 \\
\hline & Cytb & -18.044 & -15.265 & $-\alpha$ & -27.052 & -27.112 \\
\hline
\end{tabular}

${ }^{*} P<0.1$.

\section{Discussion}

Sampling strategy and geographic coverage greatly influence the analysis and interpretation of the data generated from the samples. In China, An. lesteri was distributed in a range as the east of $100^{\circ} \mathrm{E}$, and from $19^{\circ} \mathrm{N}$ to $42^{\circ} \mathrm{N}$ [14]. In this study, An. lesteri mosquitoes were collected from most localities across its range. Although field An. lesteri specimen was difficult to collect due to usage of insecticide and environment changes, our sampling still covered geographic span of An. lesteri distribution. The LN was at the most northern limit, and GD was at the most southern limit of the distribution basically.

In this study, both level of mtDNA- OII and Cytb gene nucleotide diversity in field populations were greater than JS laboratory colony, such as all Cytb sequences in JS population were the same, which was similar to other gene on mitochondrial DNA, as COI (An. dirus, An. darlingi, An. stephensi) [17-20] and COII (An. jeyporiensis, An. minimus ) [21,22]. Thus, they are useful marker for exploring An. lesteri population genetic structure.

The pairwise genetic distance using mtDNA-COII gene (0.101-0.655) was higher than Cytb (0.029-0.231). In theory, it was hard to prevent genetic divergence caused by genetic drift if the gene flow $\left[N m=\left(1-F_{S T}\right) / 4\right.$ $\left.F_{S T}\right]$ ) value was less than one [43]. The level of gene flow in these An. lesteri pairwise populations was below one, except YN/HNB, YN/LN, HNB/LN and LN/GD using mtDNA-COII gene, but all more than one except SC/YN using Cytb. The shallow population genetic structure was showed by Cytb gene. But the results by COII gene suggested that there was an apparent segregation from LN with the other populations, which is in agreement with the previous investigations with RAPD markers [13]. So, the level of An. lesteri population

Table 4 AMOVA analysis of genetic variation in Anopheles lesteri populations by mtDNA genes

\begin{tabular}{ccccccc}
\hline Source of variation & \multicolumn{2}{c}{ Degree of freedom } & Variance components & \multicolumn{3}{c}{ Percentage of variation } \\
\cline { 2 - 7 } & COII & Cytb & COII & Cytb & COII & Cytb \\
\hline Among populations & 4 & 4 & 0.433 & 0.109 & 34.17 & 11.52 \\
Within populations & 71 & 93 & 0.835 & 0.772 & 65.83 & 88.48 \\
Total & 75 & 97 & 1.268 & 0.872 & 100 & 100 \\
\hline
\end{tabular}

$F_{S T}=0.342$ (COII), 0.115 (Cytb) 
genetic divergence using mtDNA-COII gene should represent wild populations.

The factors responsible for population genetic structure should be analysed related with the climate, geography and the behaviour of mosquitoes. Yunnan is a highly complex region topographically due to its transitional position from tropical southern Himalayas to eastern Asia and from tropical Southeast Asia to subtropical China as well as at the junction of the India and Burmese plates, derived from Gondwanaland, and the Eurasian plate [44]. It is a noted centre of biodiversity [45-47]. It could have retained sufficiently mesic habitats for mosquitoes during the glaciations, when drier, more open habitats were spread widely [48]. If YN population of An. lesteri was the ancestor and the other region populations spread from Yunnan in the late stage of glaciations. The haplotype network suggested that An. lesteri migrated and spread from Yunnan towards the North and the East China, and occurred colonization and expansion during migration proceeding. They were the same as the An. lesteri population patterns with $A n$. dirus complex in Southeast Asia by mtDNA-COI and microsatellite DNA $[17,49]$, An. jeyporiensis in South China by mtDNACOII [21]. If the migrating and expansion route was true, the An. lesteri samples in south of Yunnan should be increase to further investigation. An. lesteri is widespread in Palaearctic and Oriental region, and there is different climate, breeding habitation and blood preference, such as An. lesteri in southern and central China mainly is anthropophagic, but in Liaoning preferred animal's blood [11]. The above should be the key factors of influencing population genetic structure of An. lesteri in China.

\section{Conclusion}

Levels of genetic variation within An. lesteri populations were higher than among them. There was an apparent segregation from Liaoning with the other populations using mtDNA-COII gene. The results of neutrality test suggested a large number of low-frequency mutations in populations and the populations were in expansion proceeding. While these results may suggest considerable levels of gene flow, other explanations such as the effect of historical population perturbations can also be hypothesized.

\section{Acknowledgements}

The authors thank Zhe Chen, Huayun Zhou, Xintian Lei, Yunan Gu, Guangquan Huang, Guoying Chen, Peng Li, Yaohua Shi, Liqun Huang and Yong Fan for their assistant with specimen collection. This work was funded by National Natural Science Foundation of China-Yunnan Joint Fund (U0932604), National Institutes of Health (NIH) grants R03 Al 067366 and National Natural Science Foundation of China (30571624).

\section{Authors' contributions}

YM conceived and designed the experiments. MY performed the experiments. MY and YM analyzed the data. MY and YM wrote the paper JW Provided part of the material. All authors read and approved the manuscript.

\section{Competing interests}

The authors declare that they have no competing interests.

Received: 27 January 2011 Accepted: 3 August 2011

Published: 3 August 2011

\section{References}

1. Baisas FE, Hu SMK: Anopheles hyrcanus var. sinensis of the Philippines and certain parts of China, with some comments on Anopheles hyrcanus var. nigerrimus of the Philippines. Mon Bull Bur Health 1936, 16:205-242.

2. Christophides GK: Transgenic mosquitoes and malaria transmission. Cell Microbiol 2005, 7:325-333.

3. Lehmann $T$, Licht M, Elissa N, Maega BTA, Chimumbwa JM, Watsenga F T, Wondji CS, Simard F, Hawley WA: Population structure of Anopheles gambiae in Africa. J Heredity 2003, 94:133-147.

4. Michel AP, Guelbeogo WM, Grushko O, Schemerhorn BJ, Kern M, Willard MB, Sagnon NF, Costantini C, Besansky NJ: Molecular differentiation between chromosomally defined incipient species of Anopheles funestus. Insect Mol Biol 2005, 14:375-387

5. Donnelly MJ, Simard F, Lehmann T: Evolutionary studies of malaria vectors. Trends Parasitol 2002, 18:75-80.

6. $\mathrm{Xu} J$ J, Feng LC: Studies on the Anopheles hyrcanus group in mosquitoes in China. Acta Entomol Sin 1975, 18:77-104.

7. Sandosham AA: Malariology with special reference to Malaya Singapore Singapore, University of Malay Press; 1959.

8. Ma SF: Studies on the Anopheles (A.) sinensis group of mosquitoes in China, including four new sibling species. Sinozool 1981, 1:59-70.

9. Wilkerson RC, Li C, Rueda LM, Kim HC, Klein TA, Song GH, Strickman D: Molecular confirmation of Anopheles (Anopheles) lesteri from the Republic of South Korea and its genetic identity with An. (Ano.) anthropophagus from China (Diptera: Culicidae). Zootaxa 2003, 378:1-14

10. Hwang UW, Tang LH, Kobayashi M, Yong TS, Ree HI: Molecular evidence supports that Anopheles anthropophagus from China and Anopheles lesteri from Japan are the same species. J Am Mosa Control Assoc 2006, 22:324-326.

11. Tang LH: Anopheles anthropoptagus in China: biology and control. Shanghai, Shanghai Scientific \& Technical Publishers; 2008.

12. Ma YJ, Yang P, Xu JN, Chen Z, Pan B: Identification of Anopheles lesteri in China (Diptera: Culicidae): morphologic characters, chromosome karyotype and molecular markers. Entomotaxonomia 2005, 27:199-208.

13. Ma YJ, Song GH, Li XY: Study on population genetic divergence of Anopheles anthropophagus between Liaoning and other distributions in China. Chin J Parasitic Dis Control 2002, 15:321-324

14. Lu BL: Fauna Sinica, Insect Vol.9 Diptera: Culicidae II. Beijing Science Press; 1997.

15. Shin EH, Kim TS, Lee HW, Lee JS, Lee WJ: Vector competence of Anopheles lesteri Baisas and Hu (Diptera: Culicidae) to Plasmodium vivax in Korea. Korean J Parasitol 2002, 40:41-44.

16. Tanaka K, Mizusawa K, Saugstad ES: A revision of the adult and larval mosquitoes of Japan (including the Ryukyu Archipelago and the Ogasawara Islands) and Korea (Diptera: Culicidae). Contr Amer Ent Inst 1979, 16:1-987.

17. Walton C, Handley JM, Tun-lin W, Collins FH, Harbach RE, Baimai V, Butlin RK: Population structure and population history of Anopheles dirus mosquitoes in Southeast Asia. Mol Bio Evol 2000, 17:962-974.

18. Wang D, Ma YJ, Zhou HN: Genetic variation of Anopheles dirus A and D (Diptera: Culicidae) in China: inferred by mtDNA-COI gene sequences. Chin J Parasitol Parasit Dis 2007, 5:368-371.

19. Gutiérrez LA, Gómez GF, González JJ, Castro MI, Luckhart S, Conn JE, Correa MM: Microgeograpic genetic variation of the malaria vector Anopheles darlingi Root (Diptera: Culicidae) from Córdoba and Antioquia, Colombia. Am J Trop Med Hyg 2010, 83:38-47.

20. Ali N, Hume JCC, Dadzie SK, Donnelly MJ: Molecular genetic studies of Anopheles stephensi in Pakistan. Med Vet Entomol 2007, 21:265-269. 
21. Chen B, Harbach RE, Butlin RK: Genetic variation and population structure of the mosquito Anopheles jeyporiensis in southern China. Mol Ecol 2004, 13:3051-3056

22. Chen B, Pedro PM, Harbach RE, Somboon O, Walton C, Butlin RK: Mitochondrial DNA variation in the malaria vector Anopheles minimus across China, Thailand and Vietnam: evolutionary hypothesis, population structure and population history. Heredity 2010, 1-12.

23. Jung J, Jung Y, Min GS, Kim W: Analysis of the population genetic structure of the malaria vector Anopheles sinensis in South Korea based on mitochondrial sequences. Am J Trop Med Hyg 2007, 77:310-315.

24. Ndo C, Antonio-Nkondjio C, Cohuet A, Ayala D, Kengne P, Morlais I, Awono-Ambene PH, Couret D, Ngassam P, Fontenille D, Simard F: Population genetic structure of the malaria vector Anopheles nili in subSaharan Africa. Malar J 2010, 9:161

25. Michel AP, Ingrasci MJ, Schemerhorn BJ, Kern M, Le Goff G, Coetzee M, Elissa N, Fontenille D, Vulule J, Lehmann T, Sagnon F, Costantini C, Besansky NJ: Rangewide population genetic structure of the African malaria vector Anopheles funestus. Mol Ecol 2005, 14:4235-4248.

26. Michel AP, Grushko O, Guelbeogo WM, Lobo NF, Sagnon N, Costantini C, Besansky NJ: Divergence with gene flow in Anopheles funestus from the Sudan Savanna of Burkina Faso, West Africa. Genetics 2006, 173:1389-1395.

27. Michel AP, Grushkol O, Guelbeogo WM, Sagnon N, Costantini C, Besansky NJ: Effective population size of Anopheles funestus chromosomal in Burkina Faso. Malar J 2006, 5:115.

28. Temu EA, Yan G: Microsatellites and mitochondrial genetic differentiation of Anopheles arabiensis (Diptera: Culicidae) from Western Kenya, the great rift valley, and coastal Kenya. Am J Trop Med Hyg 2005, 73:726-733.

29. Donnelly MJ, Licht MC, Lehmann T: Evidence for recent population expansion in the evolutionary history of the malaria vector Anopheles arabiensis and Anopheles gambiae. Mol Biol Evol 2001, 8:1353-1364.

30. Collins FH, Mendez MA, Rasmussen MO, Mehaffey PC, Besansky NJ, Finnerty $V$ : A ribosomal RNA gene probe differentiates member species of the Anopheles gambiae complex. Am J Trop Med Hyg 1987, 37:37-41.

31. Ma YJ, Qu FY, Cao YC, Yang BJ: On molecular identification and taxonomic status of Anopheles lesteri and Anopheles anthropophagus in China (Diptera: Culicidae). Chin J Parasitol Parasit Dis 2000, 18:325-328.

32. Tamura K, Dudley J, Nei M, Kumar S: MEGA4: molecular evolutionary genetics analysis (MEGA) software version 4.0. Mol Biol Evol 2007, 24:1596-1599.

33. Thompson JD, Gibson TJ, Plewniak F, Jeanmougin F, Higgins DG: The Clustal $\times$ windows interface: flexible strategies for multiple sequence alignment aided by quality analysis tools. Nucleic Acids Res 1997, 24:4876-4882.

34. Clement M, Posada D, Crandall KA: TCS: a computer program to estimate gene genealogies. Mol Ecol 2000, 9:1657-1660.

35. Tajima F: Evolutionary relationship of DNA sequences in finite population. Genetics 1983, 105:437-460.

36. Watterson GA: On the number of segregation sites in genetic models within recombination. Theor Popul Biol 1975, 7:256-276.

37. Schneider S, Roeddli D, Excoffier L: ARLEQUIN, Version 2.000: a software for population genetics data analysis. Genetics and Biometry Laboratory. Switzerland, University of Geneva; 2000.

38. Nei M, Li WH: Mathematical model for studying genetic variation in terms of restriction endonuclases. Proc Natl Acad Sci USA 1979, 76:5269-5273.

39. Slatkin M: A measure of population subdivision based on microsatellite allele frequencies. Genetics 1995, 139:457-462.

40. Raymond M, Rousset F: GENEPOP (version 1.2): population genetics software for exact tests and ecumenicism. J Heredity 1995, 86:248-249.

41. Schneider S, Excoffier L: Estimation of past demographic parameters from the distribution of the pariwise differences when the mutation rates vary among sites: application to human mitochondrial DNA. Genetics 1999, 152:1079-1089.

42. Powell JR, Caccone A, Amato GD, Yoon C: Rates of nucleotide substitution in Drosophila mitochondrial DNA and nuclear DNA are similar. Proc Natl Acad Sci USA 1986, 83:9090-9093.

43. Slatkin M: Gene flow and the geographic structure of natural population. Science 1987, 236:787-792.
44. Audley-Charles: In MGDispersal of Gondwanaland: relevance to evolution of the angiosperms. Biogeographical Evolution of the Malay Archipelago. Edited by: Whitemore TC. Oxford, Clarendon Press; 1987:

45. Jin ZZ, Ou XK: The diversity features of plant community types in the tropical rain forest vegetation of Xishuangbanna, Yunnan. Acta Bot Yunnan Supp/ 1997, 1:1-30.

46. Zhu H, Xu ZH, Wang $H$, Li BG: Tropical rain forest fragmentation and its ecological and species diversity changes in southern Yunnan. Biol Conserv 2004, 13:1355-1372.

47. Dong XS, Zhou HN, Gong ZD, Dong LM, Wang XZ: Investigation of mosquito species in Yunnan Province with some new species. Chin J Vector Biol Control 2004, 5:186-188.

48. Kealhofer L, Penny D: A combined pollen and phytolith record for fourteen thousand years of vegetation change in northeastern Thailand. Rew Palaeobot Palynor 1998, 103:83-93.

49. Walton C, Handley JM, Collins FH, Baimai V, Harbach RE, Deesin V, Butlin RK: Genetic population structure and introgression in Anopheles dirus mosquitoes in Southeast Asia. Mol Ecol 2001, 10:569-580.

doi:10.1186/1475-2875-10-216

Cite this article as: Yang et al:: Mitochondrial genetic differentiation across populations of the malaria vector Anopheles lesteri from China (Diptera: Culicidae). Malaria Journal 2011 10:216.

\section{Submit your next manuscript to BioMed Central and take full advantage of:}

- Convenient online submission

- Thorough peer review

- No space constraints or color figure charges

- Immediate publication on acceptance

- Inclusion in PubMed, CAS, Scopus and Google Scholar

- Research which is freely available for redistribution

Submit your manuscript at www.biomedcentral.com/submit
Biomed Central 